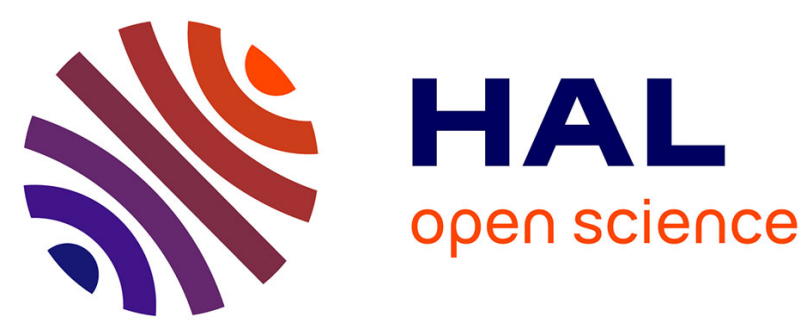

\title{
Garden compost inoculum leads to microbial bioanodes with potential-independent characteristics
}

Bibiana Cercado Quezada, Nathalie Byrne, Marie Bertrand-Huleux, Diana

Pocaznoi, Mickaël Rimboud, Wafa Achouak, Alain Bergel

\section{- To cite this version:}

Bibiana Cercado Quezada, Nathalie Byrne, Marie Bertrand-Huleux, Diana Pocaznoi, Mickaël Rimboud, et al.. Garden compost inoculum leads to microbial bioanodes with potential-independent characteristics. Bioresource Technology, 2013, vol. 134, pp. 276-284. 10.1016/j.biortech.2013.01.123 . hal-00878185

\section{HAL Id: hal-00878185 \\ https://hal.science/hal-00878185}

Submitted on 29 Oct 2013

HAL is a multi-disciplinary open access archive for the deposit and dissemination of scientific research documents, whether they are published or not. The documents may come from teaching and research institutions in France or abroad, or from public or private research centers.
L'archive ouverte pluridisciplinaire $\mathbf{H A L}$, est destinée au dépôt et à la diffusion de documents scientifiques de niveau recherche, publiés ou non, émanant des établissements d'enseignement et de recherche français ou étrangers, des laboratoires publics ou privés. 


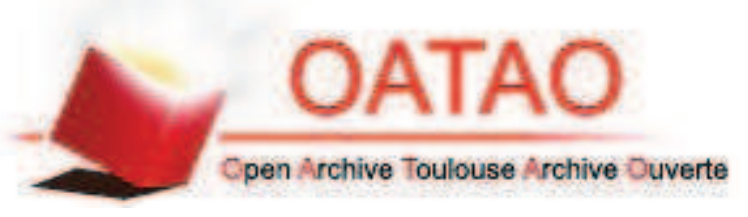

\section{Open Archive TOULOUSE Archive Ouverte (OATAO)}

OATAO is an open access repository that collects the work of Toulouse researchers and makes it freely available over the web where possible.

This is an author-deposited version published in : http://oatao.univ-toulouse.fr/ Eprints ID : 9916

To link to this article : DOI:10.1016/j.biortech.2013.01.123

URL : http://dx.doi.org/10.1016/j.biortech.2013.01.123

To cite this version : Cercado Quezada, Bibiana and Byrne, Nathalie and Bertrand, Marie and Pocaznoi, Diana and Rimboud, Mickaël and Achouak, Wafa and Bergel, Alain Garden compost inoculum leads to microbial bioanodes with potential-independent characteristics. (2013) Bioresource Technology, vol. 134 . pp. 276-284. ISSN 0960-8524

Any correspondance concerning this service should be sent to the repository administrator: staff-oatao@,1istes-diff.inp-toulouse.fr 


\title{
Garden compost inoculum leads to microbial bioanodes with potential-independent characteristics
}

\author{
Bibiana Cercado ${ }^{\mathrm{a}, 1}$, Nathalie Byrne $^{\mathrm{b}}$, Marie Bertrand ${ }^{\mathrm{b}}$, Diana Pocaznoi ${ }^{\mathrm{a}}$, Mickaël Rimboud ${ }^{\mathrm{a}}$, \\ Wafa Achouak ${ }^{\mathrm{b}}$, Alain Bergel ${ }^{\mathrm{a}, *}$ \\ a Laboratoire de Génie Chimique (LGC), CNRS, Université de Toulouse (INPT), 4 allée Emile Monso, BP 84234, 31432 Toulouse, France \\ ${ }^{\mathrm{b}}$ Laboratoire d'Ecologie Microbienne de la Rhizosphère et d'Environnements extrêmes (LEMiRE), UMR 6191, CNRS-CEA-Aix-Marseille Univ. CEA/DSV/iBEB, CEA Cadarache, \\ 13108 Saint Paul Lez Durance, France
}

- Microbial bioanodes were formed at different polarization potential from compost leachate.

- Bioanodes performance did not depend on the polarization potential.

- The lower currents produced at $-0.4 \mathrm{~V} / \mathrm{SCE}$ were due to the electrochemical kinetics.

- The dominant species of the microbial communities were identical in all bioanodes.

- Biofilms formed at the highest potential contained more variety of redox compounds.

Keywords:

Bioanode

Microbial anode

Potential

DGGE

Microbial fuel cell

\begin{abstract}
A B S T R A C T
Garden compost leachate was used to form microbial bioanodes under polarization at $-0.4,-0.2$ and $+0.1 \mathrm{~V} / \mathrm{SCE}$. Current densities were 6.3 and $8.9 \mathrm{~A} \mathrm{~m}^{-2}$ on average at -0.4 and $+0.1 \mathrm{~V} / \mathrm{SCE}$ respectively, with acetate $10 \mathrm{mM}$. The catalytic cyclic voltammetry (CV) showed similar electrochemical characteristics for all bioanodes and indicated that the lower currents recorded at $-0.4 \mathrm{~V} / \mathrm{SCE}$ were due to the slower interfacial electron transfer rate at this potential, consistently with conventional electrochemical kinetics. RNA- and DNA-based DGGE evidenced that the three dominant bacterial groups Geobacter, Anaerophaga and Pelobacter were identical for all bioanodes and did not depend on the polarization potential. Only non-turnover CVs showed differences in the redox equipment of the biofilms, the highest potential promoting multiple electron transfer pathways. This first description of a potential-independent electroactive microbial community opens up promising prospects for the design of stable bioanodes for microbial fuel cells.
\end{abstract}

\section{Introduction}

Since the pioneering studies microbial fuel cells (MFCs) have largely used marine sediments and water effluents as inoculum to form microbial bioanodes (Pant et al., 2012). Soils have been comparatively little exploited as inoculum sources so far, although they offer an abundant microbial biodiversity and should be an interesting reservoir of electroactive species (Ntarlagiannis et al., 2007). A few attempts have successfully exploited soils to form bioanodes (Kim et al., 2005; Niessen et al., 2006; Cristiani et al.,

\footnotetext{
* Corresponding author. Tel.: +33 5343236 73; fax: +33 534323700 .

E-mail address: alain.bergel@ensiacet.fr (A. Bergel).

1 Present address: Instituto Potosino de Investigación Científica y Tecnológica A.C., División de Ciencias Ambientales, Camino a la Presa San José 2055, Lomas 4a sección, CP 78210, San Luis Potosí, SLP, Mexico.
}

2008) and a recent study comparing different soils has suggested that there is promising potential (Dunaj et al., 2012).

After the inoculum and the related suitable medium have been chosen, the second question to be asked in the objective of designing a microbial bioanode concerns the value of the applied potential. Unfortunately, considerable uncertainty remains so far as to the impact of the applied potential on bioanode performance. A recent review suggested that there was a general trend towards improved performance when using more positive potentials but they have also been some notable cases where current generation improved at more negative potentials (Wagner et al., 2010). This consideration was based on studies that involved both pure and mixed cultures. A second review emphasized the inconsistency of the reported results when only mixed cultures were considered (Kumar et al., 2012). For instance, a benthic MFC generated increasing currents with increasing applied potential up to 
0.618 V vs. $\mathrm{Ag} / \mathrm{AgCl}$ (Finkelstein et al., 2006). In contrast, Aelterman et al. (2008) observed an optimal value of $-0.2 \mathrm{~V}$ vs. $\mathrm{Ag} / \mathrm{AgCl}$ that gave higher power than potentials below and above. In other studies, the power increased with increasing potential up to a threshold of around $+0.2 \mathrm{~V}$ vs. $\mathrm{Ag} / \mathrm{AgCl}$ (Wang et al., 2010) or $0.6 \mathrm{~V}$ (Srikanth et al., 2010) and decreased thereafter.

Actually, it is difficult to extract accurate conclusions on the anode behavior from experiments carried out with a complete MFC set-up, because the power produced by a MFC depends on many different parameters, including cathode thermodynamic and kinetics, $\mathrm{pH}$ and composition of the solution, ohmic drop, cell design, etc., which interact together. Going ahead in deciphering the mechanisms of bioanode formation now requires studies to be carried out in 3-electrode set-ups under well-controlled electrochemical conditions to minimize the number of interacting parameters (Kumar et al., 2012). The present study follows this logic.

In a previous work, we showed that bioanodes could be developed under constant applied potential on graphite and metal electrodes embedded in garden compost (Parot et al., 2007). Current densities up to $545 \mathrm{~mA} \mathrm{~m}^{-2}$ were reached when acetate was added and no significant effect of the polarization potential was observed in the range from 0.1 to $0.7 \mathrm{~V} / \mathrm{SCE}$ (Parot et al., 2008). Nevertheless, it was difficult to use these bioanodes out of the soil in which they were formed and they lost most of their electrochemical efficiency when transferred into a liquid medium. To overcome this disadvantage, a new procedure has been implemented that uses a leachate solution obtained by percolating the garden compost (CercadoQuezada et al., 2010a). Anodes formed in compost leachate have provided $209 \mathrm{~mA} \mathrm{~m}^{-2}$ for the oxidation of dairy wastes in MFC conditions and up to $1600 \mathrm{~mA} \mathrm{~m}^{-2}$ with the same substrate under potentiostatic control (Cercado-Quezada et al., 2010b, 2011). Recent work performed with acetate has given a stable current density of $66 \mathrm{~A} \mathrm{~m}^{-2}$ at $-0.2 \mathrm{~V} / \mathrm{SCE}$ by forming the biofilm around ultramicroelectrodes. It has been shown that the ultra-microelectrode effect was responsible for the high current density by improving the efficiency of the electron transfer network inside the biofilm (Pocaznoi et al., 2012). This previous work showed that the use of soil leachate an inoculum deserves further attention.

The purpose of the present work was to determine the effect of the polarization potential on the formation of bioanodes from leachate of garden compost. All experiments were performed under well controlled conditions in a 3-electrode set-up so as to characterize the anode behavior accurately. Anodes were formed under constant polarization at three different potential values: $-0.4,-0.2$ and $+0.1 \mathrm{~V} / \mathrm{SCE}$. Their electrochemical properties were characterized by cyclic voltammetry and their microbial community was compared by DGGE analysis. Additionally, different electrode topographies were tested. Some results were identical to those obtained with wastewater-inoculated anodes in similar experimental conditions (Torres et al., 2009), but the bioanodes formed here had electrochemical performance and microbial characteristics that were largely independent of the potential used to form them. To our knowledge, such independency of bioanode characteristics with respect to the polarization potential was observed here for the first time.

\section{Methods}

\subsection{Inoculum source}

Compost leachate was composed of a mixture of garden compost $(1 \mathrm{~L})$ and distilled water $(1.5 \mathrm{~L})$ containing $15 \mathrm{mM} \mathrm{NaCl}$. The mixture was stirred for $24 \mathrm{~h}$, filtered through a felt cloth and used after addition of $10 \mathrm{mM}$ sodium acetate. The initial $\mathrm{pH}$ was 7.4 and conductivity was $2.9 \mathrm{mScm}^{-1}$.

\subsection{Electrode material}

Carbon electrodes with different surface morphologies were obtained from PaxiTech SAS (Grenoble, France). Carbon felt was made of a compact assembly of disordered carbon fibers around $10 \mu \mathrm{m}$ in diameter. The cloth electrode used the same fibers assembled into tightly woven $300-\mu \mathrm{m}$-diameter threads. The same felt and cloth electrodes were also covered with a microporous layer (MPL-felt and MPL-cloth) composed of a mixture carbon and polytetrafluoroethylene, which formed a uniform layer including micropores in the range $100-500 \mathrm{~nm}$. SEM pictures of each surface are presented in the Supplementary data (Fig. S1).

\subsection{Microbial bioanode construction}

Microbial bioanodes were formed under constant polarization at $-0.4,-0.2$ and $+0.1 \mathrm{~V} / \mathrm{SCE}$ in 3-electrode electrochemical reactors. Potentials were controlled by a multichannel potentiostat (VSP, BioLogic Science Instrument). The working carbon electrode $\left(10 \mathrm{~cm}^{2}\right.$ projected surface area) was put into a closed reactor that contained $150 \mathrm{~mL}$ compost leachate, a platinum mesh $\left(10 \mathrm{~cm}^{2}\right)$ used as auxiliary electrode, and a saturated calomel reference electrode (SCE, $+0.241 \mathrm{~V}$ vs. SHE). All potentials are expressed with respect the SCE reference. Reactors were set in a water bath with temperature controlled at $40^{\circ} \mathrm{C}$, which was the optimal temperature determined by a previous study (Cercado-Quezada et al., 2010 b). Cyclic voltammetry (scan rates 1,10 or $100 \mathrm{mVs}^{-1}$ ) was performed at the starting polarization, at points close to the current peaks (catalytic $\mathrm{CV}$ ) and when the current levelled off to approximately zero (non-turnover CV). Three successive cycles were recorded systematically. As the second and third cycles were always identical, only the second cycles are reported here. Mature biofilms were formed by four successive acetate additions. The conditions of each experimental series are detailed in Table 1.

\subsection{Analysis and calculations}

Acetate concentration was determined with an enzymatic kit (K-Acetak, Megazyme, Inc.). Charges were calculated by integrating the recorded current over time $\left(Q_{\text {exp }}\right)$. The charges $\left(Q_{\text {theo }}\right)$ theoretically produced by acetate oxidation were calculated assuming that $1 \mathrm{~mol}$ of acetate gave $8 \mathrm{~mol}$ of electrons. Coulombic efficiencies were calculated as $Q_{\text {exp }} / Q_{\text {theo }}$. Current densities were related to the projected surface area of the working electrode $\left(10 \mathrm{~cm}^{2}\right)$.

Colonized electrodes were observed by scanning electron microscopy (SEM) at $7.5 \mathrm{kV}$ in a Leo 435VP microscope (SRV-32 software). Samples were fixed with $4 \%$ glutaraldehyde solution, post-fixed with $2 \% \mathrm{OsO}_{4}$ solution, gradually dehydrated in an acetone series (50\%, 70\% and 100\% solutions) and coated with gold before observations.

\subsection{Microbial community analysis}

Biofilms were scratched from the electrodes and the cells were then recovered from the pieces of biofilm by vigorous agitation in a sterile minimum medium (M9). The cell suspensions were therefore stored at $-80{ }^{\circ} \mathrm{C}$ (after addition of 5\% DMSO) for cultivation and total DNA/RNA extraction. Total DNA was extracted from the microbial suspensions as previously described (Parot et al., 2009). RNA was extracted using an RNA Power Soil isolation kit (MO BIO) that yielded non-degraded total RNA. In brief, cells were lysed for two cycles of 5 and 10 min with a Ribolyser cell disruptor (Retsch) in $15 \mathrm{~mL}$ bead tubes containing extraction buffer. Further extraction and precipitation were performed and pelleted nucleic acids were washed in ice-cold $70 \%(\mathrm{v} / \mathrm{v})$ ethanol, air-dried and resuspended in $20 \mu \mathrm{L}$ of RNase-free sterile water. DNA was 
Table 1

Maximum current density $\left(J_{\max }\right)$ and Coulombic efficiencies obtained for each $10 \mathrm{mM}$ acetate addition during chronoamperometries at different polarization potentials. The electrode surface area was $10 \mathrm{~cm}^{2}$ and the volume of solution $150 \mathrm{~mL}$ for each experiment.

\begin{tabular}{|c|c|c|c|c|c|c|}
\hline \multirow[t]{2}{*}{ Series No. } & \multirow[t]{2}{*}{ Potential ( $V$ vs. SCE) } & \multirow[t]{2}{*}{ Electrode } & \multicolumn{2}{|c|}{ Current density at the peak $\left(\mathrm{A} \mathrm{m}^{-2}\right)$} & \multicolumn{2}{|c|}{ Coulombic efficiency (\%) } \\
\hline & & & 3rd & 4 th & 3rd & 4 th \\
\hline \multirow[t]{4}{*}{1} & -0.4 & Carbon cloth & 5.6 & 5.5 & 43 & 51 \\
\hline & -0.4 & Carbon cloth + MPL & 6.3 & 5.1 & 59 & 53 \\
\hline & -0.4 & Carbon felt & 6.4 & 5.3 & 53 & 55 \\
\hline & -0.4 & Carbon felt + MPL & 6.7 & 6.0 & 53 & 46 \\
\hline \multirow[t]{4}{*}{2} & +0.1 & Carbon cloth & 10.5 & 12.3 & 79 & 72 \\
\hline & +0.1 & Carbon cloth + MPL & 7.1 & 8.1 & 60 & 63 \\
\hline & +0.1 & Carbon felt & 7.4 & 7.6 & 47 & 67 \\
\hline & +0.1 & Carbon felt + MPL & 8.4 & 9.4 & 59 & 64 \\
\hline \multirow[t]{4}{*}{3} & +0.1 & Carbon cloth & 8.9 & 6 & 46 & 44 \\
\hline & +0.1 & Carbon cloth + MPL & 7.2 & - & 33 & - \\
\hline & +0.1 & Carbon felt & 8.5 & 8 & 44 & 42 \\
\hline & +0.1 & Carbon felt + MPL & 8.2 & 4.9 & 40 & 41 \\
\hline \multirow[t]{4}{*}{4} & +0.1 & Carbon cloth & 8.2 & 9.5 & 34 & 34 \\
\hline & +0.1 & Carbon cloth & 8.9 & $10^{*}$ & 34 & 35 \\
\hline & +0.1 & Carbon felt & 9.0 & $10^{*}$ & 36 & 37 \\
\hline & +0.1 & Carbon felt & 9.9 & $10^{*}$ & 35 & 35 \\
\hline \multirow[t]{3}{*}{$5^{* *}$} & -0.4 & Carbon cloth & - & 8.6 & - & 52 \\
\hline & -0.2 & Carbon cloth & - & 15.3 & - & 71 \\
\hline & +0.1 & Carbon cloth & - & 14.8 & - & 70 \\
\hline 6 & -0.4 & Carbon felt & - & 7.3 & - & 43 \\
\hline \multicolumn{7}{|c|}{ Average Coulombic efficiencies (\%) } \\
\hline \multicolumn{5}{|c|}{$\begin{array}{l}-0.4 \mathrm{~V} \text { vs. SCE } \\
\text { From series \#1, } 5 \text { and } 6 \text { ( } 6 \text { independent reactors implemented with } 3 \text { fresh media) }\end{array}$} & $52 \pm 7$ & $50 \pm 5$ \\
\hline \multicolumn{5}{|c|}{$\begin{array}{l}+0.1 \mathrm{~V} \text { vs. SCE } \\
\quad \text { From series \#2, 3, } 4 \text { and } 5 \text { (13 independent reactors implemented with } 4 \text { fresh med }\end{array}$} & $46 \pm 14$ & $50 \pm 15$ \\
\hline
\end{tabular}

Limited by the electronic threshold of the potentiostat.

* Series \#5 also included three other electrodes that were extracted and analyzed at the end of the first current peak (day 6).

removed from RNA with DNase for $1 \mathrm{~h}$ at $37^{\circ} \mathrm{C}$ according to the manufacturer's recommendations (Promega, USA). 16S rRNA gene amplifications were performed using treated RNA as template to ensure that DNA was totally removed.

Reverse transcription of RNA to complementary DNA (cDNA) was performed by incubating RNA samples with random primers at $70^{\circ} \mathrm{C}$ for $10 \mathrm{~min}$. Samples of annealed primer template were then chilled on ice and $8 \mu \mathrm{L}$ of reverse transcription reaction mixture (containing SuperScript Rnase H- Reverse Transcriptase, 5X First-Stand Buffer and $0.1 \mathrm{M}$ dithiothreitol (DTT)) was added as specified by the manufacturer (Invitrogen). Reverse transcription was carried out at $42{ }^{\circ} \mathrm{C}$ for $50 \mathrm{~min}$ and the enzyme was subsequently heat-inactivated for $10 \mathrm{~min}$ at $70^{\circ} \mathrm{C}$. PCR amplification of cDNA template was performed as for DNA (see below). Denaturing gradient gel electrophoresis (DGGE) was achieved by amplification of 16S rRNA gene fragments from biofilm DNA or cDNA using a nested PCR approach as described by Haichar et al. (2007).

\section{Results and discussion}

\subsection{Chronoamperometry at different potentials}

Carbon electrodes $\left(10 \mathrm{~cm}^{2}\right.$ surface area) of various surface topographies (cloth, felt, and these materials covered by a microporous layer, see Fig. S1 in Supplementary data) were put in four reactors each filled with $150 \mathrm{~mL}$ compost leachate supplemented with $10 \mathrm{mM}$ acetate. No solution other than the raw compost leachate was added into the reactors. Bioanodes were formed at $-0.4 \mathrm{~V}$ (experimental series \#1). The chromatograms showed a first current peak around day 2 , which corresponded to the formation of the electroactive biofilm followed by a decrease in current due to acetate depletion (Fig. 1A). Successive additions of $10 \mathrm{mM}$ acetate restored the current, which reached a maximum of around $6 \mathrm{~A} \mathrm{~m}^{-2}$ regardless of the electrode (Table 1). Coulombic efficiencies (CE) were around $10 \%$ for the first peaks and in the range $43-59 \%$ for the third and fourth peaks (Table 1 ). The performance improvement that was observed with successive substrate additions was due to progressive biofilm formation and the concomitant adaptation of microbial cells to the electrode respiring mode (Liu et al., 2008). No differences were observed to depend on the different surface topographies: the shapes of the chronoamperograms and the maximum currents were identical for the four electrodes.

A second series of four experiments (series \#2) was carried out at $+0.1 \mathrm{~V}$. The general trend was similar to that observed in the experimental series \#1, but higher currents $\left(7-12 \mathrm{~A} \mathrm{~m}^{-2}\right.$ ) and higher CE values (47\% to $79 \%$ ) were obtained (Table 1 ). At the second current peak, supplementary acetate was added to each reactor, which increased the width of the current peak but did not increase the maximum current (Fig. 1B). Substrate availability was consequently not a rate-controlling step. The chronoamperograms in Fig. 1B suggest that the bioanode on carbon cloth without MPL performed better. However, the replicates (series \#3 and \#4 each including four experiments) showed no significant differences between MPL-covered and uncovered materials (Table 1). Similarly, there was no significant difference in current density with cloth and felt electrodes $\left(9.1 \pm 0.9 \mathrm{~A} \mathrm{~m}^{-2}\right.$ vs $8.7 \pm 1.0 \mathrm{~A} \mathrm{~m}^{-2}$, see series \#2, \#3 and \#4). In conclusion, regardless of the polarization potential, the bioanode performance was not affected by the electrode topography.

Each experimental series from \#1 to \#4 was performed with a fresh inoculum. To avoid possible perturbations due to different inoculum samples, the experimental series \#5 compared three polarizations: $-0.4,-0.2$ and $+0.1 \mathrm{~V}$ in six reactors run in parallel with the same inoculum. Differences in current generation startup time were observed over the first $24 \mathrm{~h}$ (Fig. 2). The start-up time decreased and the current generation rate increased when the applied polarization potential was more positive. This initial effect vanished rapidly with time, and all potentials then led to almost 

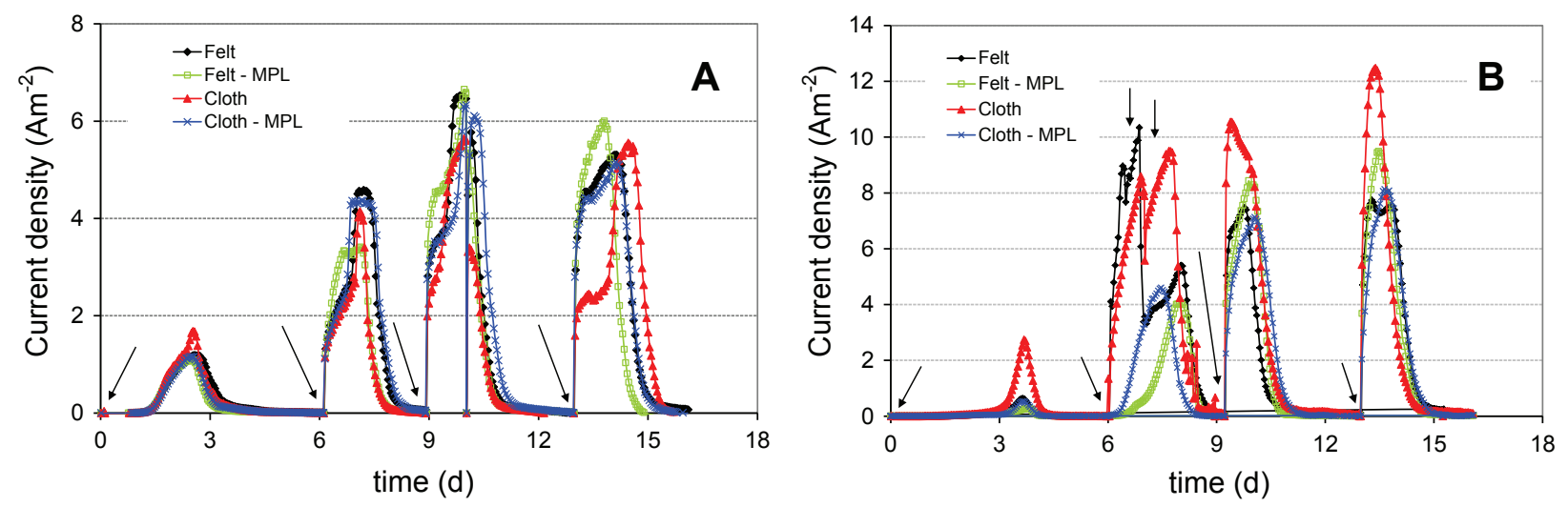

Fig. 1. Current densities during bioanode formation on electrodes with different topographies (carbon felt, MPL-carbon felt, carbon cloth, MPL-carbon cloth). Polarization at (A) $-0.4 \mathrm{~V}$ vs. SCE (series \#1); (B) $+0.1 \mathrm{~V}$ vs. SCE (series \#2). Arrows indicate the addition of $10 \mathrm{mM}$ acetate.

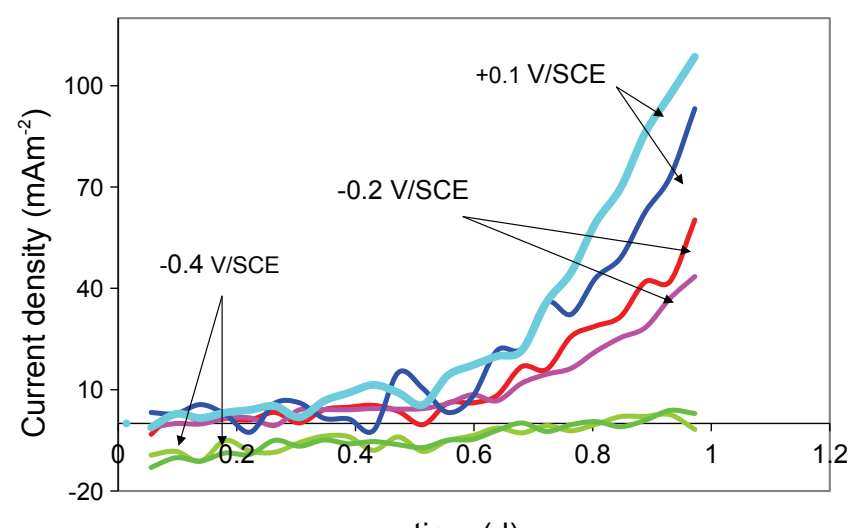

time (d)

Fig. 2. Current densities during the starting-up of bioanode formation on carbon cloth electrodes polarized at $-0.4,-0.2$ and $+0.1 \mathrm{~V}$ vs. SCE (series \#5, each potential in duplicate).

simultaneous first current peaks. At this point, one reactor from each polarization potential was stopped and the anodes used for microbial community analysis. Successive acetate additions made in the other three reactors to the 4th current peak showed that the anode at $-0.4 \mathrm{~V}$ produced a current density of $8.6 \mathrm{~A} \mathrm{~m}^{-2}$ with $\mathrm{CE}$ of $52 \%$, while at potentials of -0.2 and $+0.1 \mathrm{~V}$ the anodes generated a higher current density of approximately $15 \mathrm{~A} \mathrm{~m}^{-2}$ with CE of $70 \%$. The current evolutions were identical regardless of the potential value. In this series \#5 the current densities were slightly higher than, but consistent with, those obtained in the other experimental series.

The initial effect of the potential on the start-up time was confirmed by comparing the experimental series \#1 (at $-0.4 \mathrm{~V}$ ) and $\# 2$ (at $+0.1 \mathrm{~V}$ ) (Figs. $1 \mathrm{~A}$ and $1 \mathrm{~B}$ ). Higher potential always accelerated the initial generation of current. Differences in early current establishment depending on the potential have already been reported in the literature (Finkelstein et al., 2006; Marcus et al., 2007). It has been suggested that high potentials increase the positive surface charge and enhance the primary adhesion of negatively charged bacteria (Wang et al., 2009). This explanation could hardly be evoked here to explain the differences in current production in the first $24 \mathrm{~h}$. In a so rich a medium as the compost leachate used here, the presence of a large variety of mineral and organic compounds, which adhered on the electrode surface immediately after electrode immersion, certainly masked most electrostatic interactions.

Interestingly, Aelterman et al. (2008) did not observe a significant difference in start-up times with the applied potentials when using an inoculum composed of a microbial community that was already adapted to electricity generation. Comparing the reported data suggests that the initial characteristic of the inoculum, either wild or coming from an electricity-producing biofilm, may be a key parameter that affects the starting-up rate. The formation rate of an electroactive biofilm may be more directly linked to the ability of the initial cells to respire the anode than to electrostatic interactions. A community already adapted to electricity production would thus lead to fast start-up that would not depend on the applied potential as reported by Aelterman et al. (2008), while the time necessary for a wild community to adapt to anode respiration would depend on the applied potential as reported by Wang et al. (2009). This postulate explains the divergence from previously reported results and is supported by the observations made in this work.

In each experimental series, the anodes showed stable performance with the mature biofilms that were formed after the second acetate addition. The current density produced by the bioanodes formed at the different potentials was consequently calculated statistically with the 3rd and 4th current peaks (Table 1 ). The maximum current densities were $6.3 \mathrm{~A} \mathrm{~m}^{-2}$ at $-0.4 \mathrm{~V}$ (standard deviation $1.1 \mathrm{~A} \mathrm{~m}^{-2}, n=10$ ) and $8.9 \mathrm{~A} \mathrm{~m}^{-2}$ at $+0.1 \mathrm{~V}$ (standard deviation $\left.2.0 \mathrm{~A} \mathrm{~m}^{-2}, n=24\right)$. On the basis on these results, it can be concluded that the bioanodes formed at $-0.4 \mathrm{~V}$ provided currents on average $30 \%$ lower than those formed at $0.1 \mathrm{~V}$.

The Coulombic efficiencies (Table 1 ) varied among the experimental series, depending on the inoculum samples. On the basis of 35 measurements, considering the third and fourth acetate additions, CEs were $50 \%$ (standard deviation $13 \%, n=35$ ) without any difference associated with the polarization potential. CE values result from the balance between the electrogenic processes and the consumption of acetate by other metabolic pathways that use other electron acceptors than the anode. Rich media such as garden compost certainly contain a large amount of dissolved electron acceptors (nitrates, sulfates, humic substances, etc.), the concentrations of which vary depending on the sample. The non-controlled chemical composition of the natural medium that was used here explained the fairly large standard deviation observed on CE values extracted from 6 different experimental series, each performed with a different, fresh medium. Nevertheless, the 35 measurements did not detect a difference associated with the polarization potential, suggesting a similar microbial community in all bioanodes.

\subsection{Electrochemical characteristics of the bioanodes formed at different potentials}

During bioanode formation, the polarization was briefly interrupted and cyclic voltammetry curves (CV) were recorded. All 
catalytic CV recorded at the current peaks had similar profiles, which did not depend on the polarization potential. Fig. 3 shows the catalytic CV recorded close to the 3rd current peak during bioanode formation at $+0.1 \mathrm{~V}$ (series \#4, carbon cloth). The current density measured at $+0.1 \mathrm{~V}$ on the CV curve was equal to the current density observed during the polarization just before the $\mathrm{CV}$ was recorded, which indicated that the $\mathrm{CV}$ provided a correct representation of the stationary behavior of the electrode. The CV (Fig. 3) indicated that the electrode could provide its maximum current density from a potential of $-0.2 \mathrm{~V}$, while the current density at -0.4 was far from the maximum. At $-0.4 \mathrm{~V}$, the interfacial electron transfer rate drastically affected the global electron transfer process, while a potential of $+0.1 \mathrm{~V}$ was high enough to ensure that the interfacial kinetics was no longer a rate-limiting step. This observation confirmed that lower currents were recorded during chronoamperograms at $-0.4 \mathrm{~V}$ because the interfacial electron transfer became rate-limiting at this low potential value, according to a conventional Butler-Volmer electrochemical kinetics, with the current varying as the exponential of the applied potential.

The bioanodes had an open circuit potential below $-0.5 \mathrm{~V}$. The $\mathrm{pH}$ of the compost leachate varied from the initial value of 7.4 to around 8.3 at day 6 and to a final value around 8.6 at the end of the experiments (2-3 weeks). At $\mathrm{pH} 8.6$, the formal potential of acetate oxidation $\left(E^{0 \prime}\right)$ :

$\mathrm{CH}_{3} \mathrm{COO}^{-}+4 \mathrm{H}_{2} \mathrm{O} \rightarrow 8 \mathrm{e}^{-}+2 \mathrm{HCO}_{3}^{-}+9 \mathrm{H}^{+}$

was:

$E^{0 \prime}=E^{0}-R T / 8 F \ln \frac{a_{\mathrm{CH}_{3} \mathrm{COO}^{-}}}{\left(a_{\mathrm{HCO}_{3}^{-}}\right)^{2}\left(a_{\mathrm{H}^{+}}\right)^{9}}$

where $E^{0}$ is the standard potential of the $\mathrm{CO}_{2} /$ acetate couple $(0.187 \mathrm{~V} / \mathrm{SHE}$, Logan et al., 2006), $R$ is the gas constant $\left(8.314 \mathrm{~J} \mathrm{~mol}^{-1} \mathrm{~K}^{-1}\right), F$ is the Faraday constant $\left(96,485 \mathrm{C} \mathrm{mol}^{-1}\right), a$ are the activities of the soluble compounds in solution. Equating activities to concentrations because of their low values, gave:

$$
\begin{aligned}
E_{\mathrm{V} / \mathrm{SHE}}^{0 \prime}= & 0.187-2.3 R T / 8 F\left(9 \mathrm{pH}+\log \left(\left[\mathrm{CH}_{3} \mathrm{COO}^{-}\right]\right)\right. \\
& \left.-2 \log \left(\left[\mathrm{HCO}_{3}^{-}\right]\right)\right)
\end{aligned}
$$

Assuming concentrations of acetate and bicarbonate ions of 5 and $35 \mathrm{mM}$ respectively (values that should occur during fourth current peaks) led to $E^{0 \prime}=-0.418 \mathrm{~V} / \mathrm{SHE}$ i.e. $E^{0 \prime}=-0.659 \mathrm{~V} / \mathrm{SCE}$. This means that the open circuit potential was only $160 \mathrm{mV}$ above

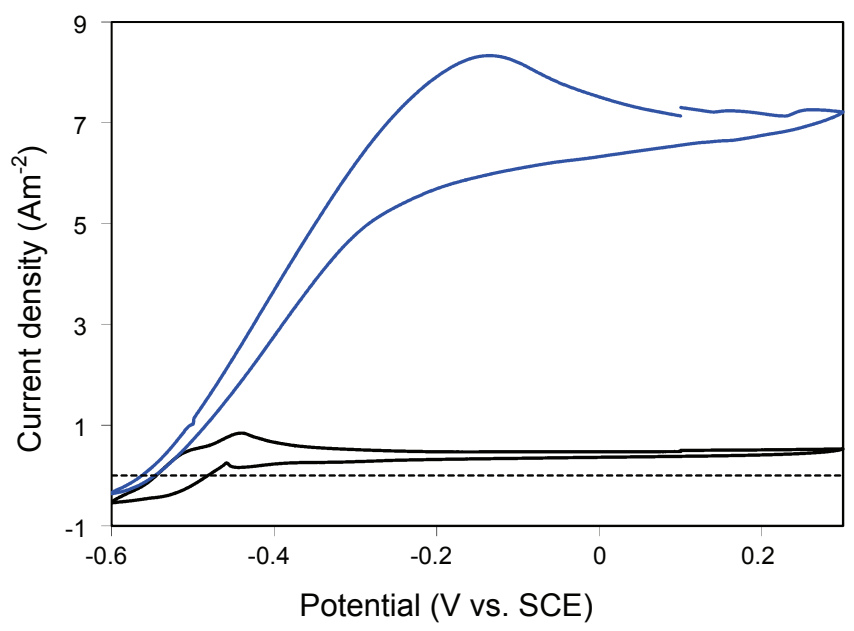

Fig. 3. Cyclic voltammetry of a bioanode formed on carbon cloth at $+0.1 \mathrm{~V}$ vs. SCE. (A) Catalytic CV (3rd current peak); (B) non-turnover CV (end of 2nd current peak). Scanning rate $1 \mathrm{mVs}^{-1}$. the formal potential of acetate oxidation, and the $-0.4 \mathrm{~V}$ polarization potential provided only $260 \mathrm{mV}$ to the microbial cells to achieve their energy metabolism (Logan et al., 2006). Even with the low energy level that was available at $-0.4 \mathrm{~V}$, the microbial cells coming from the compost leachate were able to grow and exhibited excellent electrocatalytic ability.

Non-turnover CVs were recorded during polarization when the current was near zero because of substrate depletion. In such conditions, the high current due to acetate oxidation no longer masked the low currents due to the oxidation and reduction of the redox compounds contained in the biofilm. These CVs thus gave information on the redox compounds making up the electron transfer pathways in the biofilm. Comparison of the non-turnover CV recorded before acetate addition with the following catalytic CV (Fig. 3) showed that the sharp current increase of the catalytic $\mathrm{CV}$ occurred at the same potential as the detected redox systems. It is consequently reasonable to assume that these redox systems were involved in the electron transfer pathways established during acetate oxidation.

The CVs recorded during the polarizations at $-0.4 \mathrm{~V}$ were similar for all biofilms and showed a single, well-defined redox system with potential midpoint around $-0.5 \mathrm{~V}$ (Fig. 4A). The redox system with a potential midpoint of $+0.3 \mathrm{~V}$ was not linked with the bioanode formation; it was present in the control CVs performed with clean electrodes and was due to the oxidation/reduction of surface species of the carbon electrode. The bioanodes formed at $-0.2 \mathrm{~V}$ generally led to the same kind of CV shapes. In contrast, the CVs recorded during polarizations at $+0.1 \mathrm{~V}$ showed various shapes. In some cases they exhibited a single redox system identical to those obtained at $-0.4 \mathrm{~V}$. In other cases, multiple redox systems occurred in the range -0.5 to $-0.1 \mathrm{~V}$, superimposed on the redox system centred at $-0.5 \mathrm{~V}$ that was always present. For instance, Figs. 4BE present such CVs recorded in the second series of experiments. In summary, the non-turnover CVs distinguished two different groups of biofilms. On the one hand, bioanodes formed at -0.4 and $-0.2 \mathrm{~V}$ exhibited a single redox system. On the other hand, bioanodes formed at $+0.1 \mathrm{~V}$ had less reproducible behavior, with either a similar single redox system or multiple redox systems.

\subsection{Biofilm structure and microbial composition}

SEM observations of the bioanodes formed at $+0.1 \mathrm{~V}$ during 16 days (series \#2) showed large areas of the felt electrode covered with a uniform biofilm, while the cloth electrode was significantly less colonized and mainly presented colonization around single fibers (Fig. S2 in Supplementary data). In this case, the globally less colonized electrode provided 25\% higher current density (Fig. 1B). It can be postulated that the low colonization observed around the fibers of the cloth electrode resulted in a large surface area (Chen et al., 2011), while the uniform biofilm observed on the felt surface offered a smaller free surface area and/or induced mass transfer limitation. As reported in the recent literature, controlling the electrode structure and, consequently, the biofilm structure is an appropriate way to improve the performance of microbial bioanodes (Chen et al., 2011).

Three bioanodes, each polarized at a different potential $(-0.4$, $-0.2,+0.1 \mathrm{~V}$, series \#5), were observed after the end of the first current peak ( 6 days) and at the end of the experiment after the fourth current peak ( 15 days). At day 6 , the bioanode formed at -0.4 and $-0.2 \mathrm{~V}$ showed lower colonization than those polarized at $+0.1 \mathrm{~V}$ (Fig. S3 in Supplementary data). After 15 days, the anodes polarized at $-0.4 \mathrm{~V}$ still showed less biofilm development than the other electrodes, which all exhibited similar biofilm coverage. It has already been reported that lower anode potential results in a lower amount of biomass (Aelterman et al., 2008) and this finding was confirmed here. Nevertheless, all bioanodes gave similar catalytic 

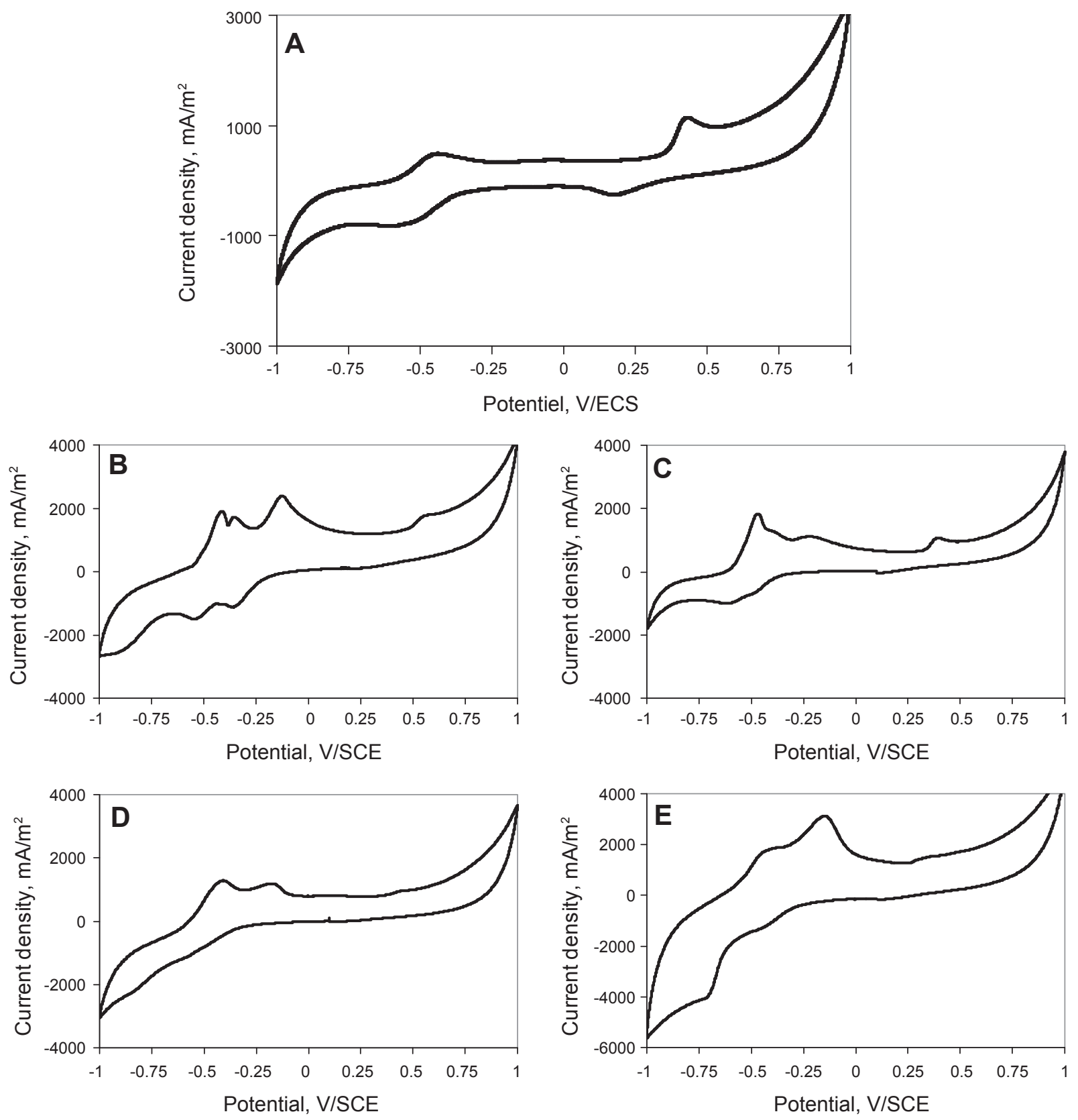

Fig. 4. Non-turnover cyclic voltammetry recorded after acetate depletion. (A) Bioanode formed at $-0.4 \mathrm{~V}$ vs. SCE (series \#1, Fig. $1 \mathrm{~A}$, day 13 ); B, C, D, and E) Bioanodes formed at $+0.1 \mathrm{~V}$ vs. SCE (series \#2, Fig. $1 \mathrm{~B}$, day 15 ). Scanning rate $10 \mathrm{mVs}^{-1}$.

CVs regardless of the polarization potential. The lower colonization did not prevent the bioanodes formed at $-0.4 \mathrm{~V}$ from producing currents similar to the others when their potential was increased to identical values. The electrocatalytic performance of the anodes was consequently not straightforwardly linked to the amount of biofilm.

The microbial populations of each bioanode from series \#5 were analyzed by DGGE. RNA- and DNA-based DGGE methods were combined, because analysis of RNA indicated which bacterial populations were active. DNA-based DGGE profiles from the bioanodes formed over 6 days at $-0.4,-0.2$ and $+0.1 \mathrm{~V}$ did not show any significant difference, as these bioanodes were mainly colonized by bacteria closely related to Pelobacter, Geobacter, Hydrogenophaga, and bacteria belonging to the Bacteriodetes/Chlorobi group such as Chlorobi sp. and Anaerophaga sp. Only one difference occurred on the electrode polarized at $+0.1 \mathrm{~V}$, which showed an intense band corresponding to a bacterial population closely related to Pelobacter acetylinicus (Fig. 5). The RNA-based DGGE profile confirmed the information obtained from the DNA and additionally indicated a high activity level of the $P$. acetylinicus population within the bioanode at $+0.1 \mathrm{~V}$.

Only slight changes were observed between bioanodes polarized for 6 and 15 days. After 15 days polarization three bacterial groups were predominant: Anaerophaga, Geobacter and Pelobacter. Bacteria related to the Pelobacter genus are often described among the predominant bacteria identified in electroactive biofilms (Freguia et al., 2010; Parameswaran et al., 2010; Kiely et al., 2011; Nercessian et al., 2012). Nevertheless, a pure culture has not yet been shown to be capable of producing current (Richter et al., 2007). In the present work, the association between Pelobacter sp. and electroactive species was confirmed for a microbial community from garden compost. RNA-based DGGE profiles indicated 


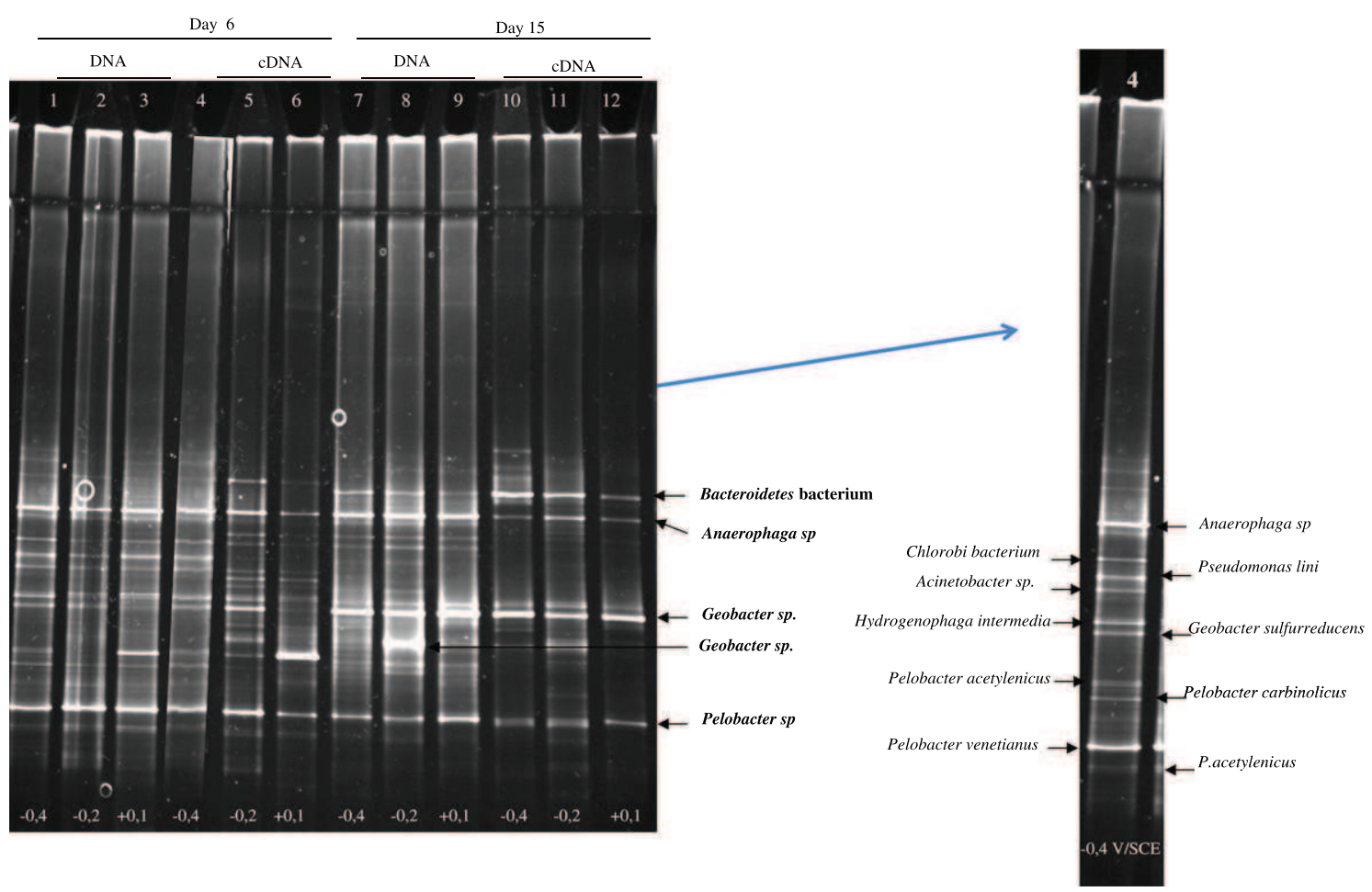

Fig. 5. (A) DGGE banding profiles of bacterial $16 \mathrm{~S}$ rRNA genes amplified from DNA (lines 1, 2, 3, 7, 8, 9) and from cDNA from RNA (lines 4, 5, 6, 10, 11, 12); (B) identification of bacterial populations from bands excised from line 4. Polarization potentials are indicated at the bottom of each line in $V$ vs. SCE (from series \#5).

that these bacterial groups had a higher activity level and also revealed a new colonizer closely related to Bacteriodetes that was not yet dominant within biofilms but was highly active. In contrast, the activity level of Anaerophage populations decreased (Fig. 5).

In summary, DGGE analyses did not show significant differences in the dominant species that made up the microbial communities of the early (6-days old, 1st current peak) and mature (15 days, 4th current peaks) bioanodes. The dominant species did not depend on the polarization potential at which the bioanodes were formed. Similar DGGE analysis of the initial solutions showed that these species could hardly be detected from the large microbial diversity that made up the initial medium, in which they were minor species. As has often been observed, the polarized electrodes exerted a strong selection on the reservoir of the initial medium.

\subsection{Discussion on the effect of the polarization potential}

Only a few works performed in 3-electrode electrochemical setups have given detailed information on the effect of potential on biofilm dynamics and composition. Finkelstein et al. (2006), working on benthic microbial anodes, have suggested that bacteria that can maximize their energy gain for a given potential have a selective advantage. Torres et al. (2009), using a mix of sludge as inoculum, reported that the lowest polarization potential $(-0.39 \mathrm{~V} /$ SCE) gave the fastest biofilm growth and a current density above $8 \mathrm{~A} \mathrm{~m}^{-2}$, while the highest potential $(0.13 \mathrm{~V} / \mathrm{SCE})$ led only to $0.6 \mathrm{~A} \mathrm{~m}^{-2}$. The authors showed that the polarization potential drastically affected the microbial communities of their bioanodes: the lowest potential induced a strong selection of a single anoderespiring-bacteria (ARB) species that achieved electron transfer exclusively through the conductive biofilm matrix, whereas the highest potential supported a more diverse microbial community including ARB and non-ARB species. At the highest potential, the $A R B$ species were able to implement different electron transfer pathways including different extracellular electron mediators. The capability of ARB to implement different electron transfer strategies in response to different polarization potentials has also been demonstrated with pure cultures (Busalmen et al., 2008; Busalmen et al., 2010).

In the present study, the polarization potential of $-0.4 \mathrm{~V}$ was only $210 \mathrm{mV}$ above the formal potential of acetate oxidation at the operating $\mathrm{pH}$. The cells captured their energy by transferring to the electrode (high potential, low free energy) the electrons they gained at lower potential (higher free energy) from acetate oxidation (Eq. (1)). The maximum amount of energy that could be obtained through this process, given by the Gibbs free energy:

$\Delta G^{0 \prime}=-8 F \Delta E^{0 \prime}$

was proportional to the difference between the anode potential and the formal potential of acetate oxidation: $\Delta E^{0 \prime}$ evaluated to $0.26 \mathrm{~V}$ (Eq. (3)) Actually, the cells could only benefit from the part of the energy between the potential of acetate oxidation and the redox potential of their terminal respiratory proteins. The cells consequently needed to possess, or tune, their respiratory enzymes to a potential as high as possible but lower than the polarization potential. The low value of the polarization potential restricted the variety of the possible options for the cells. Only the most efficient species, which were able to implement effective ARB pathways, could use the anode to grow at low applied potentials. Here, Geobacter sp. was found among the three predominant species and was probably the sole ARB species of the community. Moreover, all non-turnover CVs indicated a single redox system for the bioanodes formed at $-0.4 \mathrm{~V}$. These results confirmed that, at low potential, only the most effective ARB species grew and they developed a minimal number of redox systems.

With a similar value of applied potential $(-0.39 \mathrm{~V} / \mathrm{SCE})$, Torres et al. (2009) found identical results, but with a stronger microbial selection. The biofilms they obtained was composed of more than 
90\% Geobacter sp., while in the present work non-ARB species were also present among the dominant species. Differences in the experimental conditions can explain this discrepancy. The previous study used $300 \mathrm{~mL}$ phosphate medium with $10 \mathrm{~mL}$ of the mix of sludge used as inoculum. The concentration of dissolved electron acceptors that could have come from the inoculum was consequently very low in the final solution. In the present work, the reactors were filled with soil leachate, which certainly contained dissolved electron acceptors that could support the growth of non-ARB species. The decrease in activity of Anaerophaga detected by RNA-based DGGE after 15 days of polarization can be explained by the depletion of the dissolved electron acceptors. The bioanodes formed at $-0.4 \mathrm{~V}$, which revealed the presence of a single ARB-species and the occurrence of a single redox system, corroborated the previously reported studies, but with the presence of supplementary bacterial species due to the richness of the medium.

The bioanodes formed at $+0.1 \mathrm{~V}$ generated higher currents than the bioanodes formed at $-0.4 \mathrm{~V}$. This behavior was consistent with a conventional electrochemical kinetics, as shown by the catalytic CVs (Fig. 3), but it was drastically different from the observations made by Torres et al. (2009) who recorded lower currents when increasing the polarization potential. They showed that increasing the potential induced the development of a large variety of microbial ARB and non-ARB species. In the present work, the DGGE analysis of the bioanodes formed at $+0.1 \mathrm{~V}$ did not detect a significantly larger microbial diversity, except for the occurrence of P. acetylinicus. The soil leachate used here did not promote the development of many different species at higher polarization potential. Combining DGGE and CVs indicated that the multiple redox systems detected by $\mathrm{CV}$ on some of the biofilms formed at $+0.1 \mathrm{~V}$ were not due to the development of different bacteria but to the implementation of different electron transfer pathways by a similar bacterial community. When the polarization potential of the anode increases, the cells can implement several options to release to the anode the electrons coming from acetate oxidation. The capability of ARB to adapt to higher potential by enlarging the number of electron transfer pathways has already been shown in several studies, particularly with Geobacter sulfurreducens (Busalmen et al., 2008; Busalmen et al., 2010; Zhu et al., 2012).

The composition of electroactive microbial community formed here did not depend on the polarization potential. This original result may be due to the use of a leachate instead of the raw soil sample. Our previous studies have shown that microbial anodes formed by directly embedding electrodes in garden compost do not keep their electroactivity when transferred into solution. The microbial communities formed directly in the soils contained species related to Geobacter and Pelobacter, similarly to the observation made here, but also a larger microbial diversity, particularly with Azoarcus and Burkholderia sp. (Parot et al., 2009; Nercessian et al., 2012). The lixiviation step used here led to more restricted microbial diversity, which may have been a cause of the rather restricted microbial diversity that was observed even at high polarization potential.

To our knowledge, this was here the first description of a microbial bioanode those characteristics do not depend on the polarization potential used to form them. Designing potential-independent microbial anodes, as was done here, is of great practical interest for microbial fuel cells because their performance would not vary according to possible potential drifts during operation. Actually, the anode potential cannot be strictly fixed in a fuel cell during operation because it depends on a number of partly uncontrolled parameters like cathode kinetics, internal resistance of the cell, electrical resistance of the external circuit, fuel and oxygen supply rates, etc. It is consequently of considerable interest to develop microbial bioanodes that do not vary and do not develop less electrochemically efficient microbial communities when the anode potential drifts towards high values during operation.

\section{Conclusions}

The results presented here constitute the first demonstration that bioanodes formed in a large range of potential values can lead to similar electrochemical performance and develop a potentialindependent microbial community. The microbial community obtained here would not be affected by potential variations of the anode, which inevitably arise in microbial fuel cells or other microbial electrochemical cells during operation. This is a key advantage for obtaining stable MFC performance.

\section{Acknowledgements}

This work was part of the "Agri-Elec" project financially supported by the "Bioénergies" programme of the French Agence Nationale de la Recherche (ANR-2008-BioE-001) and the "Agrimip Sud-Ouest Innovation" Competitive Cluster. A co-author (MR) thanks the "Biorare" project (ANR-10-BTBR-02, Comité des Investissements d'Avenir) for funding.

\section{Appendix A. Supplementary data}

Supplementary data associated with this article can be found, in the online version, at http://dx.doi.org/10.1016/j.biortech.2013.01. 123.

\section{References}

Aelterman, P., Freguia, S., Keller, J., Verstraete, W., Rabaey, K., 2008. The anode potential regulates bacterial activity in microbial fuel cells. Appl. Microbiol. Biotechnol. 78, 409-418.

Busalmen, J.P., Esteve-Nuñez, A., Feliu, J.M., 2008. Whole cell electrochemistry of electricity-producing microorganisms evidence an adaptation for optimal exocellular electron transport. Environ. Sci. Technol. 42, 2445-2450.

Busalmen, J.P., Esteve-Nuñez, A., Berna, A., Feliu, J.M., 2010. ATR-SEIRAs characterization of surface redox processes in G. sulfurreducens. Bioelectrochemistry 78 (1), 25-29.

Cercado-Quezada, B., Délia, M.L., Bergel, A., 2010a. Testing various food-industry wastes for electricity production in microbial fuel cell. Bioresour. Technol. 101, 2748-2754.

Cercado-Quezada, B., Délia, M.L., Bergel, A., 2010b. Treatment of dairy wastes with a microbial anode formed from garden compost. J. Appl. Electrochem. 40, 225232.

Cercado-Quezada, B., Délia, M.L., Bergel, A., 2011. Electrochemical micro-structuring of graphite felt electrodes for accelerated formation of electroactive biofilms on microbial anodes. Electrochem. Commun. 13, 440-443.

Chen, S., He, G., Carmona-Martinez, A.A., Agarwal, S., Greiner, A., Hou, H., Schröder, U., 2011. Electrospun carbon fiber mat with layered architecture for anode in microbial fuel cells. Electrochem. Commun. 13, 1026-1029.

Cristiani, P., Franzetti, A., Bestetti, G., 2008. Monitoring of electro-active biofilm in soil. Electrochim. Acta 54, 41-46.

Dunaj, S.J., Vallino, J.J., Hines, M.E., Gay, M., Kobyljanec, C., Rooney-Varga, J.N., 2012. Relationships between soil organic matter, nutrients, bacterial community structure, and the performance of microbial fuel cells. Environ. Sci. Technol. 46 (3), 1914-1922.

Finkelstein, D.A., Tender, L.M., Zeikus, J.G., 2006. Effect of electrode potential on electrode-reducing microbiota. Environ. Sci. Technol. 40 (22), 6990-6995.

Freguia, S., Teh, E.H., Boon, N., Leung, K.M., Keller, J., Rabaey, K., 2010. Microbial fuel cells operating on mixed fatty acids. Bioresour. Technol. 101, 1233-1238.

Haichar, F.Z., Achouak, W., Christen, R., Heulin, T., Marol, C., Marais, M.F., Mougel, C., Rainjard, L., Balesdent, J., Berge, O., 2007. Identification of cellulolytic bacteria in soil by stable isotope probing. Environ. Microbiol. 9 (3), 625-634.

Kiely, P.D., Rader, G., Regan, J.M., Logan, B.E., 2011. Long-term cathode performance and the microbial communities that develop in microbial fuel cells fed different fermentation end products. Bioresour. Technol. 102, 361-366.

Kim, G.T., Hyun, M.S., Chang, I.S., Kim, H.J., Park, H.S., Kim, B.H., Kim, S.D., Wimpenny, J.W.T., Weightman, A.J., 2005. Dissimilatory Fe(III) reduction by an electrochemically active lactic acid bacterium phylogenetically related to Enterococcus gallinarum isolated from submerged soil. J. Appl. Microbiol. 99, 978-987.

Kumar, A., Katuri, K., Lenst, P., Leech, D., 2012. Does bioelectrochemical cell configuration and anode potential affect biofilm response? Biochem. Soc. Trans. 40, 1308-1314. 
Liu, Z., Li, H., Liu, J., Su, Z., 2008. Effects of inoculation strategy and cultivation approach on the performance of microbial fuel cell using marine sediment as bio-matrix. J. Appl. Microbiol. 104, 1163-1170.

Logan, B.E., Hamelers, B., Rozendal, R., Schröder, U., Keller, J., Freguia, S., Aelterman, P., Verstraete, W., Rabaey, K., 2006. Microbial fuel cells: methodology and technology. Environ. Sci. Technol. 40, 5181-5192.

Marcus, A.K., Torres, C.I., Rittmann, B.E., 2007. Conduction-based modeling of the biofilm anode of a microbial fuel cell. Biotechnol. Bioeng. 98, 1171-1182.

Ntarlagiannis, D., Atekwana, E.A., Hill, E.A., Gorby, Y., 2007. Microbial nanowires: is the subsurface "hardwired"? Geophys. Res. Lett. 34, L17305.

Nercessian, O., Parot, S., Délia, M.L., Bergel, A., Achouak, W., 2012. Harvesting electricity from Geobacter bremensis isolated from compost. Plos One 7 (3) e34216. http://dx.doi.org/10.1371/journal.pone.0034216.

Niessen, J., Harnisch, F., Rosenbaum, M., Schröder, U., Scholz, F., 2006. Heat treated soil as convenient and versatile source of bacterial communities for microbia electricity generation. Electrochem. Commun. 8, 869-873.

Pant, D., Singh, A., Van Bogaert, G., Irving, S., Poonam, O., Nigam, S., Dielsa, L. Vanbroekhovena, K., 2012. Bioelectrochemical systems (BES) for sustainable energy production and product recovery from organic wastes and industrial wastewaters. RSC Adv. 2, 1248-1263.

Parameswaran, P., Zhang, H.S., Torres, C.I., Rittmann, B.E., Krajmalnik-Brown, R 2010. Microbial community structure in a biofilm anode fed with a fermentable substrate: the significance of hydrogen scavengers. Biotechnol. Bioeng. 105, 6978.

Parot, S., Délia, M.L., Bergel, A., 2007. Forming electrochemically active biofilms from garden compost under chronoamperometry. Bioresour. Technol. 99, 48094816.

Parot, S., Délia, M.L., Bergel, A., 2008. Acetate to enhance electrochemical activity of biofilms from garden compost. Electrochim. Acta 53, 2737-2742.
Parot, S., Nercessian, O., Délia, M.L., Achouak, W., Bergel, A., 2009. Electrochemical checking of aerobic isolates from electrochemically active biofilms formed in compost. J. Appl. Microbiol. 106, 1350-1359.

Pocaznoi, D., Erable, B., Délia, M.L., Bergel, A., 2012. Ultra microelectrodes increase the current density provided by electroactive biofilms by improving their electron transport ability. Energy Environ. Sci. 5, 5287-5296.

Richter, H., Lanthier, M., Nevin, K.P., Lovley, D.R., 2007. Lack of electricity production by Pelobacter carbinolicus indicates that the capacity for $\mathrm{Fe}(\mathrm{III})$ oxide reduction does not necessarily confer electron transfer ability to fuel cell anodes. Appl. Environ. Microbiol. 73 (16), 5347-5353.

Srikanth, S., Venkata, M.S., Sarma, P.N., 2010. Positive anodic poised potentia regulates microbial fuel cell performance with the function of open and closed circuitry. Bioresour. Technol. 101, 5337-5344.

Torres, C., Krajmalnik-Brown, R., Parameswaran, P., Marcus, A.K., Wanger, G., Gorby, Y.A., Rittmann, B.E., 2009. Selecting anode-respiring bacteria based on anode potential: phylogenetic, electrochemical, and microscopic characterization. Environ. Sci. Technol. 43 (24), 9519-9524.

Wagner, R.C., Call, D.C., Logan, B.E., 2010. Optimal set anode potentials vary in bioelectrochemical systems. Environ. Sci. Technol. 44, 6036-6041.

Wang, X., Feng, Y., Ren, N., Wang, H., Lee, H., Li, N., Zhao, Q., 2009. Accelerated startup of two-chambered microbial fuel cells: effect of anodic positive poised potential. Electrochim. Acta 54, 1109-1114.

Wang, X., Feng, Y., Liu, J., Lee, H., Ren, N., 2010. Performance of a batch twochambered microbial fuel cell operated at different anode potentials. J. Chem. Technol. Biotechnol. 86, 590-594.

Zhu, X., Yates, M.D., Logan, B.E., 2012. Set potential regulation reveals additional oxidation peaks of Geobacter sulfurreducens anodic biofilms. Electrochem. Commun. 22, 116-119. 